\title{
On Selecting FL Educational Text
}

\author{
Elena Ya. Grigoryeva * (a), Valeriy I. Uvarov (b), Lyudmila P. Ryzhova (c)
}

(a) Moscow City University, 129226, Moscow (Russia), 4-1, $2^{\text {nd }}$ Selskokhoziastvenny Proezd

(b) Russian State University for the Humanities, 125993, Moscow (Russia),

6, Miusskaya sq.

(c) Moscow State Pedagogical University, 119991, Moscow (Russia), 88, Vernadsky prospect

egrig@inbox.ru

\begin{abstract}
The article attempts to analyze the texts of modern foreign language textbooks and workbooks for their relevance, to interpret the results of the study of the students' and teachers' opinions on this issue and, based on the data obtained, to offer methodologically and didactically justified approaches to the choice of a foreign language educational text for students of a non-linguistic university. The list of criteria presented according to the results of the study does not rank them according to the degree of importance, since all of them equally contribute to the formation of students' highquality foreign language communicative competence. Finally, the authors draw a conclusion about the important role of methodologically and didactically justified choice of educational text material as a basis for learning a foreign language. The authors also express the hope that taking into account the proposed selection criteria will contribute to the growth of interest in learning foreign languages.

Keywords: foreign languages, educational text, competencies.
\end{abstract}

(C) 2021 Elena Ya. Grigoryeva, Valeriy I. Uvarov, Lyudmila P. Ryzhova

This is an open access article distributed under the terms of the Creative Commons Attribution License (CC BY 4.0), which permits unrestricted use, distribution, and reproduction in any medium, provided the original author and source are credited.

Published by Moscow City University and peer-reviewed under responsibility of TSNI-2021

(Textbook: Focus on Students' National Identity)

\section{Introduction}

Modern progressive society actively develops all spheres of its life, and the national education system is no exception. Innovative technologies, the latest methodological and didactic approaches are constantly being

* Corresponding author. E-mail: egrig@ inbox.ru 
researched, developed and implemented in the teaching process. These trends of continuous modernization of the educational process are necessary for the state and society, as they allow them to keep up with the times and compete with the international community.

In our opinion, the improvement of teaching can be divided into two components:

1) continuous development of professional competencies and personal qualities of a teacher, who is a regulator of the educational process and is responsible for its quality in terms of the formation of a student's holistic personality (Janku, 2017);

2) regular updating of educational content in order to increase its effectiveness, as well as in accordance with modern goals and needs of the society.

Our research is devoted to the second of the above-mentioned global aspects of the modernization of the education system - the selection of high-quality educational content, namely, the analysis of current criteria for the selection of texts for teaching students a foreign language on the basis of a non-linguistic university.

\section{Purpose and objectives of the study}

The purpose of our study is to analyze the currently existing database of the most presented educational materials and suggest possible options for saturating it with more relevant content that meets the most modern requirements of the Federal State Educational Standard.

The ultimate goal of the study is to identify, using theoretical and empirical approaches, the most important criteria for selecting a modern foreign text for teaching students of a non-linguistic university a foreign language.

\section{Literature review}

Relatively few studies, both domestic (Artamonov B.V., Mokhova O.L., Shmeleva Z.N., etc.) and foreign (Borg S., Ellis R., etc.), have been devoted to the problem of methodological and didactic selection of the text material of a modern foreign language textbook. Most researchers identify only a few basic parameters for choosing an educational text. However, the parameters often differ. Thus, the expansion of the list of criteria and their unification seem to us even more relevant.

\section{Methodology}


Theoretical (study of pedagogical literature, analysis, synthesis and comparison) and empirical (questionnaire, survey) research methods were used in the study. The material of the study was educational texts in a foreign language, used by teachers of several leading Russian non-linguistic universities in teaching students to work with the text and the formation of their foreign language communicative competence. The respondents (during the survey) were bachelor students studying in various fields (advertising, management, psychology, economics, international relations and public relations) and teachers of foreign languages of these universities. In total, the study took into account the opinions of more than 200 representatives of the student and pedagogical community.

\section{Results}

As it was mentioned earlier, modern society is constantly evolving and requires the same from the educational environment. The regular updating of the requirements of the Federal State Educational Standards, as well as the need to implement a competence-based approach in modern education, require a revision of the parameters of the methodological and didactic selection of educational texts of a modern foreign language textbook, its adaptation to the real capabilities of universities and the needs of society.

Based on the analyzed educational texts, as well as the obtained personal data of students and teachers who gave their assessment of the content of currently used foreign language textbooks and workbooks, we identify the following relevant criteria for the selection of educational texts for the formation of foreign language competence in a non-linguistic university:

1) authenticity of the material;

2) linguistic and cultural component;

3) professional orientation;

4) informativeness;

5) practical orientation;

6) stylistic variation;

7) accessibility and adaptability;

8) the ability to correlate the educational profile with other sciences and fields of knowledge; 
9) positivity;

10) visibility of the material.

The list presented above does not rank the components according to the degree of significance, since, in our opinion, each of them is necessary for the formation of a complete student's personality through working with the educational text. Next, we will consider each of the criteria in more detail.

In the methodology of teaching foreign languages, the meaning of the term "authenticity" is constantly being clarified. As a rule, authenticity is understood as the naturalness and originality of the educational material (Mokhova, 2016). A modern text should have both compositional and linguistic authenticity, assuming logical coherence and integrity of the content, as well as the presence of lexical and grammatical units that are actually used in modern conversation by native speakers.

For the formation of foreign language competence, the original text should be accompanied by pre-text and post-text tasks aimed at working out and memorizing key vocabulary and grammatical structures, as well as identifying the degree of reading comprehension with subsequent access to the discussion. This structural approach to modelling work with text, namely, the repeated repetition of authentic content in tasks of various formats, allows students to reliably strengthen it in their long-term memory, as well as to form their skills of practical application of this material.

According to the authors, any modern educational text should include a linguoculturological component, the main task of which is to introduce students to the culture of the language and the country of its native speakers. Within the framework of this approach to the selection of the educational text, it is supposed to use in logically justified volumes the material that has a country-specific sociolinguistic orientation in order to give students the opportunity to understand the situational nature of the use of certain grammatical and lexical units (Shmeleva, 2019). For example, knowing the cultural characteristics of native speakers can significantly facilitate negotiations in business, find the right approach to solving a problem during psychological counselling, choose the right style and design of a new advertising campaign, etc. Thus, the linguistic and cultural component of the educational content also helps in the formation of students ' professional competencies (Ryzhova, 2020), preparing them for real business communication.

The formation of the necessary students' competencies should also contribute to the professional orientation of the educational text (Janku, 2017), taking into account the main nuances of the profile direction of students, which the textbook or workbook is dedicated to. To do this, the key vocabulary and a selection of texts should include professional terms already known to students and be followed by the 
gradual addition of new lexical units.

At the same time, it is important to take into account that nowadays there is often dissonance in the teaching of a foreign language and specialized disciplines - foreign language material often outstrips the knowledge obtained by students in specialized subjects. In fact, there is a real possibility that students get acquainted with the specifics of their future profession first in a foreign language class, and only then take a more detailed corresponding course in their native language (Artamonov, 2015). This is largely due to the fact that for a long time in non-linguistic universities, the study hours for learning foreign languages (more often, only one foreign language) are "absorbed" by basic and specialized subjects, depriving any professional teachers of the opportunity to form a high-quality foreign language competence among students. In addition, the reduction of hours in a foreign language creates a situation in which students complete the training of this discipline in the first or second year, while the bulk of specialized subjects begin to be taught to them from the third year.

The authors do not call for leaving the situation with an underestimation of the role of a foreign language in the formation of a complete professional personality of a graduate in such a state as it is now. However, if we still assume that in the near future the situation with the distribution of academic hours will not change for the better, it would be more logical to introduce a professional foreign language immediately after or in parallel with the teaching of specialized disciplines. Such a solution would improve the efficiency of teaching foreign languages and the quality of the educational process as a whole due to the fact that students could:

1) repeat and consolidate the material passed in the native language during the foreign language classes (Ellis, 2015);

2) see clear parallels and differences between concepts and terminology in the native and foreign languages;

3) be much more active and conscious in the course of discussions in a foreign language.

Undoubtedly, one of the most important criteria in the selection of educational foreign language text material should be its high informativeness, assuming the relevance (novelty and usefulness) of the material offered to students, which really reflects the modern realities of the professional environment in which they will have to prove themselves after graduation. A high level of information content will greatly facilitate the process of working with the text for both students and teachers, by increasing the motivation and involvement of both parties (Meskill, C., Alandeom O. (2019). Having correctly built a line of 
motivation, a professional teacher will be able to maintain it at the proper level throughout the entire training course, not only at the expense of their creative and competence potential, but also with the help of a high-quality educational text.

An equally important aspect of a foreign language text should be its practical orientation, that is, the mandatory access to practical development of theoretical knowledge in order to form all the necessary language competencies.

Any language user has a variety of skills that represent an organized set of knowledge and psychological mechanisms (Tomlinson, Masuhara, 2017). Thus, in the methodology of language teaching, there are:

- $\quad$ Linguistic competence;

- $\quad$ Encyclopaedic competence;

- Logical competence;

- $\quad$ Rhetorical and pragmatic competence.

Linguistic competence refers to the knowledge of a language, its pronunciation, its vocabulary, syntax, etc. Logical competence includes the ability to reason logically, draw conclusions, understand all the subtleties of an idea, connect ideas with each other, etc. Encyclopaedic competence involves knowledge of a diverse order, relating to the infinite variety of subjects that the language allows us to talk about. "The rhetorical and pragmatic component of communicative competence includes the ability to consciously create, pronounce and reflect the author's address text in accordance with the purpose and situation of public speech, reflects the language and speech culture of the speaker, includes the connection of language and culture, the spiritual world of the individual and genre-stylistic features of texts as products of speaking" (Gorobets, 2008).

Taking into account the balanced importance of informative content and practical orientation of the educational text, the authors propose to structure the modules of the textbook or workbook in such a way that each of them has at least one "informative" and one "practical" text. The first would give students a general idea of the module's topic, and the second (among other learning functions) would show them how to properly apply this knowledge in practice. For example, in a textbook on a business foreign language in the standard topic "Money", the second (practical) text could be devoted to the question of how to really raise the necessary capital in a relatively short time, or it might give a step-by-step description of the process of obtaining a loan (with access to the subsequent development of the material of both texts 
(informative and practical) in the format of a case or role-playing game).

An important criterion when choosing an educational text material in a foreign language should be its stylistic variability. The textbook material should be presented with texts of various genres and styles to help students create for themselves a holistic view of the language picture of the world and their professional sphere in particular. In addition to informative texts of an encyclopaedic nature, it makes sense to include clippings from authentic newspaper articles and online blogs in the structure of a textbook or training course, and to add business correspondence templates in the form of real examples. It also seems possible to have a logically based literary text, rich in relevant professional vocabulary. A variety of styles and genres will significantly increase the level of students' interest in working with this text.

The next criterion, consisting of two logically interrelated aspects, when selecting an educational text should be its accessibility and adaptability. The accessibility of the text assumes that it corresponds to the main characteristics of the target audience - age, initial level of foreign language proficiency, interests, and personal characteristics of students (Borg, 2015). Adaptability is expressed in the ability to use the same authentic text for different methodological and didactic tasks, as well as for students with different levels of foreign language competence. In other words, we are talking about a universal textbook or its individual texts that do not require significant processing, taking into account the changing characteristics of the target audience and the situation in which the training takes place. An illustrative example is the adaptability of educational texts when changing the full-time format of training to a distant or mixed one (Setzekorn, 2020). A high-quality text will be equally effective both for work in the classroom and in the framework of students' independent work.

When choosing a material for practicing reading skills of special texts, it is important to consider the possibility of correlating the educational profile with other sciences and fields of knowledge. In other words, the profile text can and should show interdisciplinary connections. Taking into account the concept of the need to balance theory and practice (Shahmohammadi, 2018), the authors assign the main role in building logical connections between the language of the future profession and other disciplines to the second (practical) text of the textbook module. In our opinion, the most suitable example for demonstrating interdisciplinary connections in a single educational text can be the symbiosis of specialized and psychological contents. So, in a business foreign language textbook in the topic "Negotiations", the second text may be devoted to how (from the point of view of personality psychology) to influence a business partner or client and make them accept your terms of the deal.

Since many things in modern society depend on a certain set of behavioral patterns and motivations of 
people, according to the authors, the analysis of the psychological side of the issue is relevant for texts of any profile-oriented topic.

No matter how pathetic it may sound, the authors distinguish among others the criterion of the positivity of the content of the educational text. It is important to clarify that positivity in the educational text is needed not mainly for additional motivation of students, but rather for creating a positive working atmosphere and removing possible stress factors associated with learning a foreign language. The second goal of an emotionally positive context is to distract students from thinking about the difficulties and problems of everyday reality and to focus their attention on the learning process that promotes life-affirming ideas. It is important not to create illusions among students that it is possible to avoid all difficulties in life, but it should be emphasized that dedication and diligence can help in solving many problems and to achieve personal and professional success.

Modern generations of students differ significantly from the previous ones (Ary, Jacobs, Irvine, Walker, 2018). This is natural and logical. Many of the participants of the modern educational process can not imagine their life without television and the Internet. (Meskill, Anthony, Sadykova, 2020). From the point of view of psychology, there is a strong interest of students to the educational material that has the greatest visibility. It is imaginative thinking and visualization that come to the fore, and it would be wrong not to use this aspect for methodological purposes. Thus, it is useful to focus students' attention by adding various illustrations and tables to the educational text, which makes it possible to solve several methodological and didactic tasks at once:

1) students subconsciously associate the text with an image, which can become a code for the subsequent reproduction of the text or its main content;

2) students acquire the skills of describing images and discussing the plot of illustrations;

3) if we are talking about the presentation of grammar in the form of tables or figures, this greatly simplifies the understanding and assimilation of the educational material.

\section{Discussions}

The presented results of the study, in our opinion, cover in more detail the range of aspects that should be taken into account when choosing a foreign-language educational text. Systematization and unification of selection parameters should contribute to the creation of better educational content not only on the basis of higher education, but also at other levels of teaching. Moreover, according to the authors, the proposed list of criteria can be synchronized with all the humanities, as well as with many others related to various fields 
of science.

\section{Conclusion}

In conclusion, the authors would like to draw attention to the fact that the selection of high-quality educational text material is not just an important condition for effective teaching of the discipline, but also a huge responsibility. Designed on the basis of high-quality selected text material, taking into account all the above-mentioned criteria, a foreign language textbook or any other discipline will always be positively accepted by students and convenient for the teacher.

The appearance of a larger number of high-quality educational texts will increase the level of students' motivation to study, will contribute to the development of their curiosity and desire to read additional literature in a foreign language. On the basis of carefully selected and elaborated authentic texts, it is possible to build any creative activity of students, including the technologies of project and game activity that are particularly relevant in our time.

\section{References}

Artamonov, B.V. (2015). Some problems of teaching foreign languages in non-linguistic universities. Modern scientific researches and innovations, 12 Retrieved from http://web.snauka.ru/en/issues/2015/12/61489

Ary, D., Jacobs L.C., Irvine C.K.S., Walker D. (2018). Introduction to research in education. Harcourt Brace College Publishers.

Borg, S. (2015). Teacher cognition and language education: Research and practice. London: Bloomsbury Publishing.

Ellis, R. (2015). Understanding Second Language Acquisition, Second Edition. Oxford: Oxford University Press.

Gorobets, L.N. (2008). Rhetorical competence of the teacher: problems of research and practice of formation. Proceedings of the A. I. Herzen Russian State Pedagogical University, 62, 214-218.

Janku, M. (2017). Intercultural learning and methodical — didactical aspect. European science review, 1-2. Retrieved from https://cyberleninka.ru/article/n/intercultural-learning-and-methodical-didacticalaspect 
Janku, M. (2017). The teacher, as a cultural mediator between two languages. Austrian Journal of Humanities and Social Sciences, 1-2. Retrieved from https://cyberleninka.ru/article/n/the-teacheras-a-cultural-mediator-between-two-languages

Meskill, C., Alandeom O. (2019). Meeting the Challenges of English Learners by Pairing Science and Language Educators. Research in Science Education, 49, 122-136. https://doi.org/10.1007/s11165019-9837-9.

Meskill, C., Anthony, N., Sadykova, G. (2020). Teaching languages online: Professional vision in the making. University of Hawaii National Foreign Language Resource Center, 24 (3), 160-175.

Mokhova, O.L. (2016). The problem of authenticity in the selection of texts for professionally oriented reading training. Vestnik Moskovskogo gosudarstvennogo lingvisticheskogo universiteta. Education and pedagogical Sciences, 4 (743), 77-84. Retrieved from https://cyberleninka.ru/article/n/problema-autentichnosti-pri-otbore-tekstov-dlya-professionalnoorientirovannogo-obucheniya-chteniyu

Ryzhova, L., Grigorieva, E., Dorofeeva, I. (2020). Linguopragmatic Aspect of Intercultural Communication. 822-831. https://doi.org/10.15405/epsbs.2020.11.03.87.

Setzekorn, K. (2020). Socioeconomics, Diversity, and the Politics of Online Education. Hershey, PA: IGI Global. https://doi.org/10.4018/978-1-7998-3583-7

Shahmohammadi, S. (2018). Textbook Evaluation: Looking at Prospect Series through Teachers' Perspective." Research in English Language Pedagogy, 6 (2), 182-204.

Shmeleva, Z.N. (2019). The formation of cross-cultural competence of students-managers by means of the foreign language learning at the non-linguistic university. ANI: pedagogy and psychology, 2 (27), 271-275. Retrieved from https://cyberleninka.ru/article/n/the-formation-of-cross-culturalcompetence-of-students-managers-by-means-of-the-foreign-language-learning-at-the-nonlinguistic-university

Tomlinson, B., Masuhara, H. (2017). The complete guide to the theory and practice of materials development for language learning. John Wiley \& Sons. 